\title{
Article
}

\section{How prepared are foundation dentists for independent general dental practice at 40 weeks of foundation training?}

Ray, Mark, Milston, Anne Marie, Doherty, Paul William and Crean, Stjohn

Available at https://clok.uclan.ac.uk/34179/

Ray, Mark, Milston, Anne Marie orcid iconORCID: 0000-0002-7491-5639, Doherty, Paul William orcid iconORCID: 0000-0003-3463-9112 and Crean, Stjohn orcid iconORCID: 0000-0001-9336-8549 (2018) How prepared are foundation dentists for independent general dental practice at 40 weeks of foundation training? Faculty Dental Journal, 9 (1). pp. 30-38. ISSN 2042-6852

It is advisable to refer to the publisher's version if you intend to cite from the work. http://dx.doi.org/10.1308/rcsfdj.2018.30

For more information about UCLan's research in this area go to

http://www.uclan.ac.uk/researchgroups/ and search for <name of research Group>.

For information about Research generally at UCLan please go to http://www.uclan.ac.uk/research/

All outputs in CLoK are protected by Intellectual Property Rights law, including Copyright law. Copyright, IPR and Moral Rights for the works on this site are retained by the individual authors and/or other copyright owners. Terms and conditions for use of this material are defined in the policies page. 
How prepared are foundation dentists for independent general dental practice at 40 weeks of foundation training?

by Mark Ray, Anne Milston, Paul Doherty, St John Crean

Authors: Mark Ray, General Dental Practitioner, Ravat and Ray Dental Care; Anne Milston, Academic Associate Course Leader, University of Central Lancashire; Paul Doherty, Senior Lecturer in Education Studies, University of Central Lancashire; and St John Crean, ${ }^{\star}$ Executive Dean of the Faculty of Clinical and Biomedical Sciences, University of Central Lancashire

${ }^{*}$ Corresponding author:

E: screan@uclan.ac.uk

Duplication: Felt vs believed vs were of the opinion of vs stated vs thought vs perceived

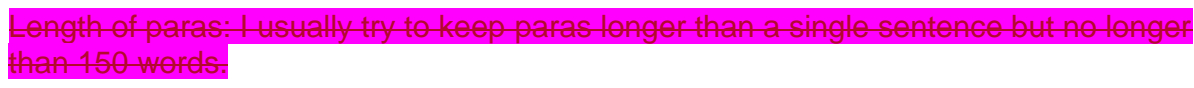

Some historical reports have expressed concerns that undergraduate dental education produces graduates who lack key skills or attributes, ${ }^{1,2}$ and dental foundation training (DFT) emerged to address the perceived gap between student and professional life. ${ }^{3} \mathrm{New}$ graduates feel it is a good introduction to general practice, especially for those considerperceived to have lower confidence. ${ }^{4}$ Despite being viewed asconsidered a 'finishing school' for dentists, some authors contend that DFT is providing core practice and instruction that should have been delivered in dental schools. ${ }^{5}$

Graduates entering DFT come fromboth UK and overseas schools. Although UK schools must all demonstrate compliance with General Dental Council (GDC) curricular requirements and overseas schools must be deemed equivalent by the GDC to allow practice, they inevitably approach the educational experience in different ways.

Consequently, graduates entering DFT are a heterogeneous group and their preparedness varies considerably across the undergraduate curriculum. ${ }^{6}$ DFT is ideally positioned to take this heterogeneous group and produce dentists who are all well prepared to practise dentistry independently in the UK, taking newly trained dentists and turning them into successful general dental practitioners.

Undergraduate skill coverage is closely linked with graduate confidence, which differs between dental schools. ${ }^{7}$ Newly qualified dentists reportperceive a lack of training in their undergraduate course in certain key areas ${ }_{2}$ including dental extractions and endodontics, which matches deficiencies highlighted by their supervisors. ${ }^{2,8,9}$ This correlates with reports of low confidence in these clinical areas. ${ }^{7,10,11}$

In $2016,80 \%$ of the final--year students at a single dental school felt unprepared for the clinical work presented in a questionnaire. ${ }^{12}$ In a study investigating What I Wish I'd Learned At Dental Schoof-, the most frequent areas in which respondents felt they needed more undergraduate instruction were business and practice management, oral surgery and endodontics; these were broadly aligned with the areas in which they sensperceived a shortfall in skills on graduation. ${ }^{13}$ It has been postulated that dDiscrepancies for reported preparedness between educational supervisors (ESs) and foundation dentists (FDs) in 
diagnosis and treatment planning represent a lack of selfawareness in the trainees' ability. ${ }^{2}$

Despite the importance of examining the preparedness of new graduates across all curricular areas, this has only been done recently = using the Graduate Assessment of Preparedness for Practice (GAPP) questionnaire in a survey across England and Wales at six weeks of DFT. ${ }^{6}$ This study showed that both FDs and ESs believed that FDs were generally well prepared for independent general dental practice (GDP) but that they were less prepared for orthodontic appliance repair and surgical extractions. ESs also deemed the trainees were less prepared for the management of temporomandibular joint (TMJ) disorders. However, several respondents felt that TMJ management and orthodontics were outside the remit of DFT.

FDs ranked their preparedness for independent GDP higher than ESs in all of the other areas of the curriculum. ${ }^{6}$ ESs with more supervisory experience ranked their FDs lower in almost all curricular areas than those with less supervisory experience_-although this was independent of the level of postgraduate GDP experience.

FDs who graduated from four-year courses felt more prepared across the curriculum than those from five-year courses. ${ }^{6}$ Similarly, those qualifying from outside the UK felt less prepared than FDs from UK schools (especially in the areas of referral, prescription of drugs, medical emergencies, teamwork and self-development).

The present study sought to re-examine the preparedness of the same FD cohort towards the end of DFT, when trainees are poised to enter truly independent practice.

Furthermore, we wanted to investigate whether DFT has achieved its aim of ensuring 'that dentists completing the programme have developed into competent, caring, reflective practitioners who can consistently provide safe and effective care for patients in a primary care setting'. 1

\section{Methods}

GAPP questionnaires were distributed in the second week of May 2012, at approximately 40 weeks of DFT. They were accompanied by participant information sheets detailing completion and return instructions, and highlighting the confidential nature and potential value of the study. University ethical approval was granted, and permission from the Chair of the Committee of Postgraduate Dental Deans and Directors (COPDEND) was obtained to distribute the GAPP questionnaire to all 74 DFT schemes in England and Wales.

The GAPP questionnaire comprises three sections. Part 1 collected demographic data including sex, age, school of qualification and length of course (4 or 5 years). The ES questionnaire also asked about length of experience as an ES and whether or not the ES had completed vocational training, whereas the question on course length was omitted. Two additional questions were added to the 40-week survey to establish whether or not the respondents had completed the 6-week questionnaire and whether or not they felt they/their FD were/was more or less prepared than at the beginning of DFT.

Part 2 included 34 questions representing all 4 domains of Preparing for Practice. ${ }^{14}$ These questions were unchanged from the questionnaire used at 6 weeks. The seven-point Likert scale allowed definitive categorical responses, which were coded to enable statistical analysis $(1=$ completely unprepared, 2 = very poorly prepared, $3=$ poorly prepared, $4=$ 
not well nor poorly prepared, $5=$ well prepared, $6=$ very well prepared, $7=$ completely prepared). The comments column meant respondents could elaborate on their categorical response for each question.

Part 3 of the GAPP questionnaire was designed to allow respondents to further expand and develop their Part 2 responses. It included questions around the FD's educational preparation for DFT and independent GDP.

Questionnaire bundles were posted to each DFT scheme's training programme director (TPD). Each bundle comprised an introduction and information sheet for the TPD, 15 copies each of the GAPP questionnaire and participant guides for FDs and ESs, and 2 stamped addressed envelopes for returning the completed questionnaires.

FDs were asked to deliver the questionnaires to their ESs and return them when completed to the TPD in order to enable their return to the researcher. Both ES and FD questionnaires were provided in unmarked, unsealed A5 envelopes to preserve confidentiality and anonymity of responses.

\section{Statistical analysis}

The coded quantitative categorical data from Part 2 were analysed with SPSS ${ }^{\circledR}$ version 20 (IBM, New York, US). Median scores were recorded for each question for FDs and ESs. Mean rank scores were generated in order to cross-tabulate Part 2 results with Part 1 descriptive data. This also allowed statistical comparison of FD and ES responses using non-parametric tests in SPSS ${ }^{\circledR}$. The Mann-Whitney U test was employed for two unrelated variables, whereas the Kruskal-Wallis $\mathrm{H}$ test was used for three-variable analyses. Following the latter, the step-down process was used as post hoc analysis to identify significant pairings. Differences in mean rank scores were considered to be statistically significant if the $p$-value was $\leq 0.05$.

All comments received in Part 2 of the questionnaire were explored on a question-byquestion basis, and considered with reference to the respondent's answers given in Parts 1 and 2. Part 3 data were analysed thematically using NVivo version 10 (QSR, Melbourne, Australia), facilitated by word frequency analysis on a question-by-question basis. The context of these themes was examined using the 'references' tool to ensure their relevance.

\section{Results}

Overall, 1,110 questionnaires were sent to 74 DFT schemes (15 per group) to ensure coverage of the 928 FDs allocated a place for this academic year. ${ }^{15} \mathrm{~A}$ total of 182 questionnaires were returned from FDs and 142 from ESs, representing response rates of $20 \%$ and $15 \%$ respectively, which were significantly lower than the $48 \%$ and $36 \%$ achieved at 6 weeks of DFT. ${ }^{6}$

\section{Respondent demographics}

The mean age of FD respondents was 25.3 years (standard deviation [SD]: 2.7 years, range: $23-37$ years). Of the $182 \mathrm{FDs}, 56 \%$ were female. The majority had graduated from a UK school (93\%) and had completed a $\underline{5}$-year course (87\%).

The ES respondents had a mean age of 45.1 years (SD: 9.4 years, range: $29-87$ years) and $18 \%$ were female [The authors's MS says $18.1 \%$ female and $89.9 \%$ male but this doesn't equal $100 \%$ !]. The mean length of experience as an ES was 7.4 years (SD: 5.6 
years, range: 1-24 years). Their mean year of qualification was 1991 (SD: 9.0 years) and the range was 1971-2007. The majority had graduated from a UK school (94\%) and had participated in vocational training (62\%).

A large majority (87\%) of FDs and more than half (52\%) of ESs who participated in the study at 40 weeks had also responded to the questionnaire at 6 weeks. ${ }^{6}$ The FD demographic data in the present study were similar to the data at six weeks, with a slight decrease $(3 \%)$ in female respondents and those from $\underline{5}$-year courses $(5 \%)$. The ES demographic data were also similar - the only difference being a large increase in female ES respondents (from 18\% at 6 weeks to $18 \%$ female at $40 \mathrm{wks}$ ?]).

Almost all FDs (98\%) thought they were better prepared towards the end of DFT, with a mere $2 \%$ feeling there had been no change. Only $87 \%$ of ESs were of the opinion that their FD was better prepared, with $7 \%$ stating there was no change and $7 \%$ feeling the FDs were less well prepared than at $\underline{6}$ weeks.

\section{Preparedness at 40 weeks vs 6 weeks of DFT}

The results obtained using the GAPP survey at $\underline{6}$ weeks ${ }^{6}$ were compared with those in this study obtained from the same cohort of respondents at 40 weeks, and are displayed in Table 1.

This was the case for every question in the ES survey but for several of the FDs' questions, there was no apparent difference between questionnaires. These were orthodontic assessment, local anaesthesia, extractions, periodontal therapy, medical emergencies and population-based care, communication with patients and the public, and management relating to self.

\section{Differences between FD and ES perceptions of preparedness}

At 40 weeks, the median scores for all but two questions were the same for ESs and FDs: For acute patient management and management relating to others, FDs felt 'very well prepared' whereas their ESs felt they were 'well prepared'. Both FDs and ESs felt that FDs were 'very well prepared' for independent practice in more than half of the 24 clinical areas, with most other areas being ranked 'well prepared'. Only orthodontic appliance repair was ranked lower ('not well or poorly prepared') by both groups.

In the communication, management and professionalism domains, FDs described themselves as 'very well prepared' in all areas. ESs agreed for

the most part; the one exception was management in relation to others ${ }_{2}$ in which they felt their FDs were 'well prepared'.

When examining the mean rank scores, the general trend was that FDs tended to rate their preparedness higher than ESs. This was significant for the management domain $(p=0.007)$ and those questions illustrated in Table 2.

\section{Sex}

There were no significant differences between ESs and FDs attributable to sex.

\section{ES year of qualification}

ESs were grouped for statistical analysis using the same descriptor used in the six-week questionnaire to facilitate comparison. They were Group 1: 1971-1987; Group 2: 19881997; and Group 3: 1998-2008. 
When considering all the questions together, there was a significant difference in response depending on the length of time ESs had been qualified. The group order was $2<1<3$ and post hoc step-down analysis showed the significant difference lay between Groups 1 and 2 (combined) and Group 3. Those ESs who had qualified most recently (1998-2008) ranked their FDs as having significantly higher preparedness $(p=0.047)$ and this held for the $\underline{5}$ individual questions in Table 3.

\section{ES experience}

ESs were grouped for statistical analysis using the same descriptor used in the six-week survey to facilitate comparison. These were Group 1: 1-3 years; Group 2: 4-8 years; and Group 3: $\geq 9$ years.

\section{Country of qualification}

FDs' schools of qualification were split into UK (93\%) and non-UK (7\%). Although UK graduates tended to feel more prepared, the only significant difference was seen for orthodontic appliance repair $(p=0.011)$.

The ES's distribution was UK $=94 \%$ and non-UK $=6 \%$. UK-qualified ESs felt that FDs were significantly more prepared only in TMJ management $(p=0.043)$.

\section{Course length}

The majority (87\%) of FDs were from $\underline{5}$-year courses, and the only significant difference was seen in history-taking, where they felt more prepared than those on 4year courses $(p=0.017)$.

\section{Part 2 comments}

The Part 2 comments column was used infrequently, with only $5.5 \%$ of FDs and $14.1 \%$ of ESs commenting. The most common themes related to orthodontics, where respondents felt it was a postgraduate subject and the practice did not carry out orthodontics. Several FD comments related to having done little or no surgical extractions in the year.

\section{Part 3 results}

Part 3 responses were analysed thematically and results considered in pairs as the ES and FD questions were closely related.

When asked in what aspects FDs felt well prepared_ and in which areas did their ESs feel they were strong_-FDs clearly placed a heavy emphasis on clinical work, with their placements in outreach, hospital and community settings classified as very important. They also considered themselves well prepared in communication skills, treatment planning and simple restorative work. ESs agreed they were good communicators and proficient at simple restorative work._They were deemed to be professional, possess good theoretical knowledge and management skills, and strong in history_taking, record-keeping and treatment-planning.

When asked about the areas that FDs felt less prepared for_and areas ESs said their FDs struggled with), FDs were concerned with the lack of clinics and clinical exposure at undergraduate level. There was particular concern at their preparation in terms of extractions - especially surgicals and (multirooted) endodontics . It was feared that there was insufficient complex indirect restorative work (crowns, bridges and dentures). They felt underprepared in treatment-planning and for the GDP environment; including the N $\underline{\mathrm{HS}}$ 
system (banding and money), management and the business side of dentistry. ESs were worried about FDs' lack of preparation for extractions (especially surgicals), multirooted endodontics and other complex restorative work. There were many references to difficult/complex/demanding treatments for which FDs were unprepared. There were also doubts about the ability of FDs to formulate treatment plans.

When asked whether or not DFT had covered their identified areas of need for independence, the overwhelming response from ESs and FDs was that there were no unfulfilled areas in the DFT year.

\section{Discussion}

Although the respondent groups both in the 6- and 40-week GAPP questionnaires came from the same population pool, the respondent populations were dissimilar. Coupled with the reduced response rates in the latter, care must be taken in results interpretation. The very similar demographics from both surveys and the high number of respondents reporting their participation in the first survey led us to believe cautious comparisons of the data are reasonable.

We postulate the lower response rate may be linked to the study day programmes drawing to an end at the time of the second questionnaire, which was central to the distribution methodology of the questionnaires _ particularly as FDs were the conduit for ES questionnaire delivery. In addition, survey fatigue in DFT is a concern for the primary gatekeeper to the populations, COPDEND (personal communication).

\section{Are FDs more prepared or less prepared at 40 weeks than at 6 weeks?}

The additional question on the 40-week GAPP questionnaire regarding the change in preparedness during the DFT year showed that $98 \%$ of FDs felt they were better prepared towards the end of DFT, with only $2 \%$ feeling there was no change. The latter respondents' comments in Part 3 gave an insight into their thoughts around this ('Certain procedures I haven't done enough of to feel fully competent to work independently [eg tricky crown and bridge work]').

The majority (87\%) of ESs also felt that their FDs were better prepared during this time period. Half of the remaining ESs felt there was no change, and the other half reported less well-prepared FDs than at the start of the DFT year. One ES commented: 'Very subjective - but if not focused, quick-acting andable to make rapid clinical decisions, they will struggle to fulfil a unit of dental activity [UDA] target without some clinical compromises.'

There appears to be concern that the FDs in these practices may struggle in the NHS system as independent practitioners. It is hoped that the few ESs who do have concerns communicate them to their FDs and TPDs, thereby allowing improvement plans to be instigated.

\section{Differences between FD and ES perceptions of preparedness}

In the 6-week GAPP questionnaire, FDs ranked their preparedness significantly higher than ESs in 32 of the 34 questions in Part $2 .{ }^{6}$ This may be due to inaccuracies in FDs' self-assessments, ${ }^{16}$ lack of self-awareness in their ability, ${ }^{2}$ inaccurate assessments of FD preparedness by $\mathrm{ESs}^{17}$ or a combination of these. 
In the questionnaire at 40 weeks - although the general trend was also for FDs to rank their preparedness higher than $\mathrm{ES} s$ - there were very few significant differences.

Consequently, it would appear that ratings of preparedness between ESs and FDs have converged over the DFT year against the backdrop of preparedness ratings having increased in both populations.

If inflated self-assessment of an FD's own ability is responsible for the discrepancies between the survey results at 6 and 40 weeks, this may indicate that the DFT year has led to an increase in insight into their abilities.

\section{ES year of qualification}

At six weeks of DFT, there appeared to be little significant difference in ratings of FD preparedness depending on the GDP experience of their ESs. ${ }^{6}$ In the present study, the general trend was the same, with the most recently qualified ESs (1998 and later) rating their FDs as more prepared. Unlike the variables in the earlier survey, however, there appeared to be a greater effect attributable to ES year of qualification, rather than a convergence.

In the 40-week questionnaire, less experienced ESs rated their FDs more prepared in safeguarding, patient and public safety, population-based care, development of self and others, and management relating to self; none of which are clinical disciplines. It may be that ESs felt able to develop the hands-on skills of their FDs during DFT but were less confident in their development of non-clinical areas. This could be owing to the attitudinal nature involved in some of the areas highlighted ${ }_{2}$ which may not be easily identified, taught or self-corrected.

The apparent late emergence in this identification by experienced ESs may highlight that areas such as this are more subtle in their presentation and more difficult to assess by other clinicians, particularly those with less experience. Competencies such as selfmanagement and self-development may also rely on significant environment-specific experiences that may become more apparent when other simpler skills are becoming mastered at a greater rate.

\section{ES experience}

We have postulated that more experienced ESs may be able to judge the preparedness of FDs more accurately. ${ }^{6}$ Those who have been repeatedly exposed to new graduates may be more attuned to the changing face of contemporary undergraduate education, and its suitability for preparing graduates for the evolving environment of GDP.

That said, the more experienced the ESs, the more distant their own contemporary thought processes are from that of their FDs, whose relatively novel cognitive abilities may be harder to recognise as cognisant with their own. This highlights the importance of testing ES experience as general practitioners and the experience of ESs as DFT supervisors, although both will necessarily coexist in more experienced supervisors.

Towards the beginning and end of DFT, the trend was for more experienced ESs to rank their FDs as less prepared. This was significant in all domains at six weeks ${ }^{6}$ and in all but the communication domain in this questionnaire, indicating that more experienced ESs feel that FDs are significantly better at communicating towards the end of DFT.

At individual question level, the results were more complex and are displayed in Table 5. Some areas reported to be less well prepared by more experienced ESs in the six-week 
questionnaire ${ }^{6}$ remained so in the later questionnaire, whereas other areas 'converged' and differences between more and less experienced ESs were no longer present. There were also areas that were not found to be significant in the first questionnaire but that emerged at this stage of DFT as being significantly less well prepared in the eyes of the more experienced ESs. This complex phenomenon requires further study to establish the underlying reasons. Further work is required to establish whether these are areas in which less progress appears to have been made by FDs during their DFT year or areas in which FDs lack insight into their performance.

\section{Conclusions}

This study demonstrates that at 40 weeks of DFT, ESs and FDs across England and Wales agree that FDs are more prepared for independent GDP than at 6 weeks. Furthermore, the assessments of preparedness made by FDs and ESs across the curriculum appear to have converged. This is against the backdrop of new graduates already being considered well prepared for independent GDP by the same respondent group. ${ }^{6}$

There was still a discrepancy between ES and FD perceptions of FD preparedness in areas including management and teamwork ${ }_{2}$ as well as history taking, treatment planning, local anaesthesia, and dentures. Certainly, some of this may be attributed to managing increasingly more complex cases as experience increases. There will always be challenges to managing more complex patient needs, no matter how experienced practitioners are. The insight of FDs is essential to the realisation of this and may differ significantly across the FD population.

This study was unable to assess the impact of the DFT programme on this increased preparedness, compared with the effect a year in GDP would have alone. Whatever the cause, the results of the GAPP questionnaires at 6 and 40 weeks of DFT may serve to reassure stakeholders in the apparent preparedness of those entering independent GDP after foundation training.

The clinical areas in which ESs felt their FDs were still not as prepared for independent practice were periodontal therapy, local anaesthesia, endodontics and indirect restorations. Although one may have predicted the appearance of complex areas such as endodontics and advanced indirect work, even perhaps the satisfactory management of often refractory diseases like periodontitis, it was somewhat surprising to see the appearance of what one may consider a fundamental and basic procedure like the provision of local anaesthesia.

The outlying areas in which there still appeared to be significant differences between ES and FD ratings of preparedness towards the end of DFT require more detailed analysis to understand better how either undergraduate training, DFT or both can be improved to further a more reflective and responsive training pathway. This will optimise the early preparation of new graduates into competent independent general dental practitioners for the future.

\section{References}

1. Cabot LB, Radford DR. Are graduates as good as they used to be? Br Dent J 1999; 186: 318-319. 
2. Patel J, Fox K, Grieveson B, Youngson CC. Undergraduate training as preparation for vocational training in England: a survey of vocational dental practitioners' and their trainers' views. Br Dent J 2006; 201: 9-15

3. Levine RS. Experience, skill and knowledge gained by newly qualified dentists during their first year of general practice. Br Dent $J$ 1992; 172: 97-102.

4. Ralph JP, Mercer PE, Bailey H. A comparison of the experiences of newly qualified dentists and vocational dental practitioners during their first year of general dental practice. Br Dent J 2000; 189: 101-106.

5. Clow R, Mehra S. Evaluation of vocational training of dentists in three different regions. Br Dent J 2006; 201: 774-778.

6. Ray M, Milston A, Doherty P, Crean S. How prepared are foundation dentists in England and Wales for independent general dental practice? Br Dent J 2017; 223 359-368.

7. Bartlett DW, Coward PY, Wilson R et al. Experiences and perceptions of vocational training reported by the 1999 cohort of vocational dental practitioners and their trainers in England and Wales. Br Dent J 2001; 191: 265-270.

8. Greenwood LF, Townsend GC, Wetherell JD, Mullins GA. Self-perceived competency at graduation: a comparison of dental graduates from the Adelaide PBL curriculum and the Toronto traditional curriculum. Eur J Dent Educ 1999; 3: 153-158.

9. McGrath CM, Corbet EF. Do dental graduates of the University of Hong Kong (1997-2001) perceive themselves prepared for dental practice? Hong Kong Dent $J$ 2005; 2: 84-91.

10. Kay EJ, Blinkhorn AS. Scottish dental students' views on their undergraduate training. Br Dent J 1987; 162: 317-319.

11. Murray FJ, Blinkhorn AS, Bulman JS. An assessment of the views by recent graduates on their undergraduate course. Eur J Dent Educ 1999; 3: 3-9.

12. Gilmour AS, Welply A, Cowpe JG et al. The undergraduate preparation of dentists: confidence levels of final year dental students at the School of Dentistry in Cardiff. Br Dent J 2016; 221: 349-354.

13. Oliver GR, Lynch CD, Chadwick BL et al. What I wish l'd learned at dental school. Br Dent J 2016; 221: 187-194.

14. General Dental Council. Preparing for Practice. London: GDC; 2012.

15. Dental Health Education England Advisory Group. Dental Foundation Training Report. 2013.

http://www.copdend.org/data/files/Foundation/Dental\%20Foundation\%20Training\% 20Report.pdf (cited November 2017).

16. Tousignant M, DesMarchais JE. Accuracy of student self-assessment ability compared to their own performance in a problem-based learning medical program: a correlation study. Adv Health Car Sci Educ Theory Pract 2002; 7: 19-27.

17. Bush HM, Schreiber RS, Oliver SJ. Failing to fail: clinicians' experience of assessing underperforming dental students. Eur J Dent Educ 2013; 17: 198-207.

Table 1 
GAPP questionnaire part 2 data at 6 and 40 weeks of dental foundation training

\begin{tabular}{|c|c|c|c|c|c|}
\hline \multirow[t]{3}{*}{ Question } & \multicolumn{4}{|l|}{ Median } & Form \\
\hline & \multicolumn{2}{|l|}{ FD respondents } & \multicolumn{3}{|l|}{ ES respondents } \\
\hline & 6 weeks & 40 weeks & 6 weeks & 40 weeks & \\
\hline \multicolumn{6}{|l|}{ Clinical domain } \\
\hline History taking & 6 (IQR: 5-6) & 6 (IQR: 6-7) & 5 (IQR: 5-6) & 6 (IQR: 5-6) & \\
\hline Patient examination & 5 (IQR: 5-6) & 6 (IQR: 5-6) & 5 (IQR: 5-5) & 6 (IQR: 5-6) & \\
\hline Orthodontic assessment & 5 (IQR: 4-5) & 5 (IQR: 4-5) & 4 (IQR: 4-5) & 5 (IQR: 4-5) & \\
\hline Acute patient management & 5 (IQR: 5-5) & 6 (IQR: 5-6) & 5 (IQR: 4-5) & 5 (IQR: 5-6) & \\
\hline Special tests & 5 (IQR: 5-6) & 6 (IQR: 5-6) & 5 (IQR: 5-5) & 6 (IQR: 5-6) & \\
\hline Diagnosis & 5 (IQR: $5-6)$ & 6 (IQR: 5-6) & 5 (IQR: 4-5) & 6 (IQR: 5-6) & \\
\hline Treatment planning & 5 (IQR: 5-6) & 6 (IQR: 5-6) & 5 (IQR: 4-5) & 6 (IQR: 5-6) & \\
\hline Prevention advice & 6 (IQR: $5-6$ ) & 6 (IQR: $5-7$ ) & 5 (IQR: 5-6) & 6 (IQR: 6-7) & \\
\hline Referrals & 5 (IQR: 5-6) & 6 (IQR: 5-6) & 5 (IQR: 4-5) & 6 (IQR: 5-6) & \\
\hline Safeguarding & 5 (IQR: 4-5) & 5 (IQR: 5-6) & 4 (IQR: 4-5) & 5 (IQR: 5-6) & \\
\hline Drug prescription & 5 (IQR: 5-6) & 6 (IQR: 5-6) & 5 (IQR: 4-5) & 6 (IQR: 5-6) & \\
\hline Periodontal therapy & 6 (IQR: 5-6) & 6 (IQR: 5-6) & 5 (IQR: 5-6) & 6 (IQR: 5-7) & \\
\hline Local anaesthesia & 6 (IQR: 6-7) & 6 (IQR: 6-7) & 5 (IQR: 5-6) & 6 (IQR: $5-7)$ & \\
\hline Direct restorations & 6 (IQR: 5-6) & 6 (IQR: 5-7) & 5 (IQR: 4-5) & 6 (IQR: 5-7) & \\
\hline Endodontics & 5 (IQR: 5-6) & 6 (IQR: 5-6) & 5 (IQR: 4-5) & 6 (IQR: $5-7)$ & \\
\hline Extraction & 6 (IQR: 5-6) & 6 (IQR: 3-5) & 5 (IQR: 4-5) & 6 (IQR: 5-7) & \\
\hline Surgical extraction & 4 (IQR: 3-5) & 5 (IQR: 4-5) & 4 (IQR: 3-5) & 5 (IQR: 5-6) & \\
\hline Dentures & 5 (IQR: 4-5) & 5 (IQR: 5-6) & 4 (IQR: 4-5) & 5 (IQR: 5-6) & \\
\hline Indirect restorations & 5 (IQR: 4-5) & 5 (IQR: 5-6) & 4 (IQR: 4-5) & 5 (IQR: 5-6) & \\
\hline Orthodontic appliance repair & 4 (IQR: 3-4) & 4 (IQR: 3-5) & 3 (IQR: 3-4) & 4 (IQR: 3-5) & \\
\hline TMJ management & 4 (IQR: 3.25-5) & 5 (IQR: 4-5) & 4 (IQR: 4-5) & 5 (IQR: 4-5) & \\
\hline Patient and public safety & 5 (IQR: 5-6) & 6 (IQR: $5-6)$ & 5 (IQR: 4.5-5.5) & 6 (IQR: 5-6) & \\
\hline Medical emergencies & 5 (IQR: $5-6)$ & 5 (IQR: 5-6) & 5 (IQR: 4-5) & 5.5 (IQR: 5-6) & \\
\hline Population-based care & 5 (IQR: $5-6)$ & 5 (IQR: 5-6) & 5 (IQR: 4-5) & 5 (IQR: $5-6)$ & \\
\hline \multicolumn{6}{|l|}{ Communication domain } \\
\hline Patients and the public & 6 (IQR: 5-7) & 6 (IQR: 5-7) & 5 (IQR: 5-6) & 6 (IQR: 5-7) & \\
\hline Other healthcare professionals & 5 (IQR: 5-6) & 6 (IQR: 5-6) & 5 (IQR: 5-6) & 6 (IQR: 5-6) & \\
\hline Generic communication skills & 6 (IQR: 5-6) & 6 (IQR: 5-7) & 5 (IQR: 5-6) & 6 (IQR: 5-7) & \\
\hline \multicolumn{6}{|l|}{ Professionalism domain } \\
\hline Patients and the public & 6 (IQR: 5-7) & 6 (IQR: 6-7) & 5 (IQR: 5-6) & 6 (IQR: 5-7) & \\
\hline Ethical and legal & 6 (IQR: $5-7)$ & 6 (IQR: 6-7) & 5 (IQR: 5-6) & 6 (IQR: $5-7$ ) & \\
\hline Teamwork & 6 (IQR: 5-7) & 6 (IQR: 6-7) & 5 (IQR: 5-6) & 6 (IQR: 5-7) & \\
\hline Development of self and others & 6 (IQR: 5-7) & 6 (IQR: 6-7) & 5 (IQR: 5-6) & 6 (IQR: 5-7) & \\
\hline \multicolumn{6}{|l|}{ Management and leadership domain } \\
\hline Relating to self & 6 (IQR: 5-7) & 6 (IQR: 5-7) & 5 (IQR: 5-6) & 6 (IQR: 5-7) & \\
\hline Relating to others & 5 (IQR: 5-6) & 6 (IQR: 5-6) & 5 (IQR: 4-5) & 5 (IQR: 5-6) & \\
\hline Relating to the working environment & 5 (IQR: 5-6) & 6 (IQR: 5-7) & 5 (IQR: 4-5) & 6 (IQR: 5-6) & \\
\hline
\end{tabular}

$\mathrm{ES}=$ educational supervisor; FD = foundation dentist; GAPP = Graduate Assessment of

Preparedness for Practice; IQR = interquartile range; TMJ = temporomandibular joint

Table 2

Questions where FD ranked preparedness was significantly higher than ESs

\begin{tabular}{|l|l|l|l|}
\multirow{2}{*}{ Question } & Mean rank & $\boldsymbol{p}$-value \\
\cline { 2 - 4 } & FD respondents & ES respondents & \\
\hline History taking & 172.02 & 150.30 & 0.027 \\
\hline Orthodontic assessment & 173.21 & 148.77 & 0.012 \\
\hline Treatment planning & 173.45 & 148.46 & 0.011 \\
\hline Local anaesthesia & 172.62 & 149.53 & 0.018 \\
\hline Dentures & 171.00 & 151.61 & 0.044 \\
\hline Teamwork & 171.77 & 150.61 & 0.032 \\
\hline Management relating to others & 178.52 & 141.96 & $<0.001$ \\
\hline
\end{tabular}

Formatted: Not Highlight

Formatted: Not Highlight 
Management relating to the

working environment

$\mathrm{ES}=$ educational supervisor; FD = foundation dentist

Table 3

Questions where least experienced educational supervisors rated their foundation dentists as significantly better prepared

\section{Question}

Safeguarding

Patient and public safety

Population-based care

Development of self and others

Management relating to self

\begin{tabular}{|l|l|} 
& Mean rank \\
\cline { 2 - 2 } & $\mathbf{1}$ \\
\hline & 77.57 \\
\hline & 73.08 \\
\hline & 67.41 \\
\hline & 66.56 \\
\hline
\end{tabular}

\begin{tabular}{|l|l|l|}
\hline \multicolumn{2}{l|}{} & $\boldsymbol{p}$-value \\
\hline 56.98 & $\mathbf{3}$ & \\
\hline 59.20 & 77.57 & 0.012 \\
\hline 63.79 & 81.16 & 0.028 \\
\hline 64.93 & 83.73 & 0.038 \\
\hline 61.67 & 83.83 & 0.045 \\
\hline
\end{tabular}

\section{Table 4}

The impact of educational supervisor experience on their ranking of foundation dentist preparedness

\begin{tabular}{|c|c|c|c|c|}
\hline \multirow[t]{2}{*}{ Question } & \multicolumn{3}{|c|}{ Mean rank } & \multirow[t]{2}{*}{ p-value } \\
\hline & 1 & 2 & 3 & \\
\hline Patient examination & 81.35 & 72.96 & 60.42 & 0.035 \\
\hline Orthodontic assessment & 83.18 & 71.55 & 60.27 & 0.018 \\
\hline Special tests & 83.55 & 66.89 & 65.18 & 0.046 \\
\hline Prevention advice & 83.69 & 64.56 & 67.68 & 0.037 \\
\hline Drug prescription & 85.24 & 69.25 & 60.90 & 0.010 \\
\hline Periodontal therapy & 82.58 & 70.37 & 62.18 & 0.042 \\
\hline Local anaesthesia & 87.23 & 63.80 & 65.16 & 0.005 \\
\hline Endodontic treatment & 81.50 & 72.65 & 60.63 & 0.041 \\
\hline Indirect restorations & 84.27 & 70.22 & 60.73 & 0.014 \\
\hline Population-based care & 83.02 & 72.12 & 59.78 & 0.017 \\
\hline Other healthcare professionals & 79.51 & 74.90 & 59.99 & 0.045 \\
\hline Ethical and legal & 82.11 & 75.48 & 56.85 & 0.006 \\
\hline Teamwork & 82.02 & 71.35 & 61.61 & 0.047 \\
\hline Development of self and others & 82.27 & 74.70 & 57.58 & 0.008 \\
\hline Relating to self & 84.30 & 70.76 & 60.10 & 0.013 \\
\hline Relating to the working environment & 85.27 & 69.17 & 60.96 & 0.010 \\
\hline
\end{tabular}

\section{Table 5}

Areas in which more experienced educational supervisors felt their foundation dentists were significantly less well prepared $t$

\begin{tabular}{|l|l|}
\hline Questionnaire at 6 weeksQuestionnaire 1 & Questionnaire at 40 weeks Questionnaire \\
\hline Questionnaire at 6 weeks?] & 2[Questionnaire at 40 weeks?] \\
\hline Clinical domain & Patient examination \\
\hline Patient examination & Orthodontic assessment \\
\hline Orthodontic assessment & Drug prescription \\
\hline Special tests & Periodontal therapy \\
\hline Diagnosis &
\end{tabular}

Formatted: Not Highlight

Formatted: Not Highlight

Formatted: Not Highlight

Formatted: Not Highlight

Formatted: Not Highlight

Formatted: Not Highlight
Formatted: Highlight

Formatted: Highlight

Formatted: Highlight

Formatted: Highlight

Formatted: Highlight 


\begin{tabular}{|l|l|}
\hline Treatment planning & Extraction \\
\hline Local anaesthesia & Indirect restorations \\
\hline Direct restorations & Population-based care \\
\hline Extraction & \\
\hline Dentures & \\
\hline Indirect restorations & \\
\hline Orthodontic appliance repair & \\
\hline TMJ management & \\
\hline Patient and public safety & \multicolumn{2}{|l|}{} \\
\hline Communication domain & Patients and the public \\
\hline Patients and the public & \\
\hline Other healthcare professionals & \\
\hline Generic communication skills & \multicolumn{2}{|l|}{} \\
\hline Professionalism domain & Patients and the public \\
\hline Patients and the public & Ethical and legal \\
\hline Ethical and legal & Teamwork \\
\hline Teamwork & Development of self and others \\
\hline Development of self and others & Relating to self \\
\hline Management and leadership domain & Relating to others \\
\hline Relating to self & Relating to the working environment \\
\hline Relating to the working environment & \\
\hline &
\end{tabular}

